\title{
Influence of the diameter of single-walled carbon nanotube bundles on the optoelectronic performance of dry-deposited thin films
}

\author{
Kimmo Mustonen, Toma Susi ${ }^{*}$, Antti Kaskela, Patrik Laiho, Ying Tian, \\ Albert G. Nasibulin and Esko I. Kauppinen ${ }^{*}$
}

\section{Full Research Paper}

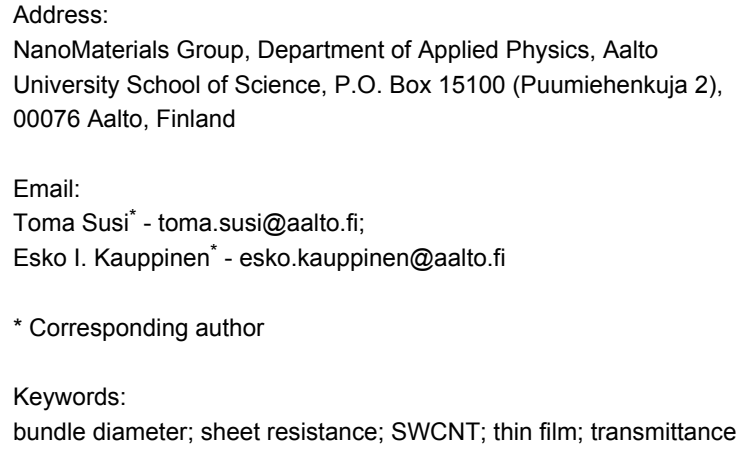

\author{
Beilstein J. Nanotechnol. 2012, 3, 692-702. \\ doi:10.3762/bjnano.3.79 \\ Received: 01 August 2012 \\ Accepted: 01 October 2012 \\ Published: 17 October 2012 \\ Associate Editor: A. Gölzhäuser \\ (C) 2012 Mustonen et al; licensee Beilstein-Institut. \\ License and terms: see end of document.
}

\begin{abstract}
The optoelectronic performance of thin films of single-walled carbon nanotubes (SWCNTs) was studied with respect to the properties of both individual nanotubes and their bundles. The SWCNTs were synthesized in a hot wire generator aerosol reactor, collected by gas filtration and dry-transferred onto various substrates. By thus completely avoiding liquid dispersion steps, we were able to avoid any artifacts from residual surfactants or sonication. We found that bundle lengths determined the thin-film performance, as would be expected for highly resistive bundle-bundle junctions. However, we found no evidence that contact resistances were affected by the bundle diameters, although they did play a secondary role by simply affecting the absorption. The individual SWCNT diameters and their graphitization level as gauged by the Raman D band intensity did not show any clear correlation with the overall performance.
\end{abstract}

\section{Introduction}

Single-walled carbon nanotubes (SWCNT) offer great application potential in future electronics, such as micro-electromechanical devices [1], sensors [2,3], transparent electrodes [4-6], thin-film field-effect transistors [7,8] and capacitors [9]. However, most methods of fabricating devices rely on dispersion of the nanotubes in solutions. While the techniques are suitable for research, process-induced damage, such as tube cutting due to sonication $[10,11]$, or residual surfactants severely limit device performance. Structural features such as SWCNT length, degree of bundling, and bundle length, diameter and orientation have received less attention, despite the fact that the electrical resistance of a SWCNT network is thought to 
be dominated by intertube and interbundle contact resistances $[6,12]$. Understanding the impact of these properties is crucial for gaining a fundamental understanding of the origins of optimal device performance and for the development of improved synthesis and deposition methods.

Synthesis and sample preparation techniques can have a strong impact on SWCNT network performance. Depending on the synthesis method, the nanotubes can have varying degrees of crystallinity, not to mention variation in the individual SWCNT and bundle length and diameter characteristics. Additional cleaning and purification steps can be detrimental for SWCNT network performance, especially in the case of sonication (cutting), acid cleaning (unintentional doping) or surfactantbased dispersions (residual surface contamination) [13,14]. Characteristic features have been explored previously by geometric scaling arguments and by comparing the performance of SWCNT films fabricated by different synthesis and sample-preparation routes. For example, Hecht et al. induced mechanical damage to liquid-suspended SWCNT bundles synthesized with the arc discharge and laser ablation methods, and were thus able to control the bundle lengths and diameters to some extent [14]. Geng et al. conducted a more thorough comparison between the performances of SWCNT networks from chemical vapor deposition (CVD), HiPCO, laser ablation, and arc discharge sources; although, again involving liquid suspensions [15]. While these initial studies have been steps in the right direction, the damage induced by sample preparation and the pervasive presence of surfactant material on the tubes limits the possibility to draw definite conclusions. More recently, Nirmalraj et al. (2009) worked with contact-mode atomic force microscopy (C-AFM) towards a direct measurement of the relation between bundle diameters and contact resistances [12]. However, due to their sample fabrication method it is likely that residual doping and surfactants were present in the samples, impacting on the results of their measurements.

By comparison, aerosol CVD synthesis offers a unique platform to study the impact of bundle characteristics on the performance of SWCNT networks, enabling direct deposition of highly pure and crystalline SWCNT bundles of varying length and diameter on a wide range of substrates. This renders the liquid dispersion unnecessary, enabling a clearer elucidation of the effects of bundle characteristics alone. The technique has yielded world-record-performance SWCNT films over a wide range of thicknesses from sub-monolayer networks for thin-film transistor channels [8], to high-performance, optically transparent electrodes $[6,16]$. Quite recently, both dry deposition of aerosol-synthesized tubes and SWCNTs from liquid dispersion have been shown to compete, and even exceed, the perfor- mance of indium tin oxide (ITO) coatings on plastic substrates in terms of optoelectronic performance [6,17]. Moreover, ITO has multiple additional drawbacks, including a high refractive index, spectrally nonuniform optical transmission, very limited flexibility, restricted chemical robustness, and most importantly, depleting raw material supply $[18,19]$.

In this contribution, we focus on an investigation on the effects of the properties of individual SWCNTs and their bundles on the optoelectronic performance of SWCNT thin films, i.e., their network conductivity and absorption. We utilize a hot-wiregenerator (HWG) [20] aerosol CVD reactor to fabricate films of SWCNTs with a wide range of bundle diameters and lengths using the dry deposition technique $[6,16]$. Also, a set of data from films previously fabricated in a similar manner by utilizing a ferrocene-based aerosol CVD reactor [21] is included for comparison. The bundle lengths are shown to dominate the optoelectronic performance, while bundle diameters play a secondary role by affecting the absorption. The diameters of the SWCNTs and their graphitization level do not seem to be important characteristics in our samples.

\section{Experimental \\ Experimental setup}

A hot wire generator (HWG) floating catalyst method was used to synthesize SWCNTs, which were subsequently utilized to fabricate SWCNT thin films. A complete description of the reactor design can be found elsewhere [22]. Briefly, iron particles were produced by vaporization from a resistively heated iron wire (current $2.7 \mathrm{~A}$, diameter $250 \mu \mathrm{m}$, purity $99.95 \%$, Goodfellow, USA) in a $\mathrm{H}_{2} / \mathrm{Ar}(7 / 93$ mol ratio) flow of $480 \mathrm{~cm}^{3} \cdot \mathrm{min}^{-1}$ inside an aluminium oxide $\left(\mathrm{Al}_{2} \mathrm{O}_{3}\right)$ tube (inner diameter $16 \mathrm{~mm}$ ). Particles formed and grew through vapor nucleation-condensation and coagulation processes inside an $\mathrm{Al}_{2} \mathrm{O}_{3}$ tube reactor (inner diameter $22 \mathrm{~mm}$ ) and were mixed with $500 \mathrm{~cm}^{3} \cdot \mathrm{min}^{-1} \mathrm{CO}$, together with $1300 \mathrm{ppm}$ of $\mathrm{CO}_{2}$, in the heated section of the furnace. The mixing zone resided $29 \mathrm{~cm}$ from the bottom inlet of the reactor, corresponding to wall temperatures of $460-700{ }^{\circ} \mathrm{C}$. The aerosol concentration was monitored at the reactor outlet with a GRIMM Vienna Type differential mobility analyzer (DMA) and a Faraday cup electrometer (SMPS+E). The catalyst source was fixed in a temperature zone in which carbon nanotube growth is known to be possible [23], corresponding to a wall temperature of $700{ }^{\circ} \mathrm{C}$ (at a depth of $29 \mathrm{~cm}$ ). The position of the HWG was kept constant, while the furnace temperature $\left(T_{\text {set }}\right)$ was varied.

\section{Sample preparation}

Samples of SWCNTs with different characteristics were synthesized by systematically varying the furnace set temperature, $T_{\text {set }}$. The true maximum furnace temperature was 10 to $15^{\circ} \mathrm{C}$ 
Table 1: Properties of SWCNT films fabricated in this study, along with four datasets from the literature.

\begin{tabular}{|c|c|c|c|c|c|c|c|}
\hline Method & $T_{\text {set }}\left({ }^{\circ} \mathrm{C}\right)$ & $I_{\mathrm{G}} / I_{\mathrm{D}}$ & $d_{\text {bundle }}(\mathrm{nm})$ & $L_{\text {bundle }}(\mu \mathrm{m})$ & $d_{\text {tube }}(n m)$ & $K\left(\mathrm{k} \Omega^{-1}\right)$ & $K_{\text {NORM }}(\mu \mathrm{m} \cdot \mathrm{k} \Omega)^{-1}$ \\
\hline HWG & 550 & 5.2 & - & - & $\approx 1.0$ & - & - \\
\hline HWG & 600 & 5.2 & - & - & $\approx 1.0$ & - & - \\
\hline HWG & 650 & 7.6 & $3.1 \pm 1.0$ & $0.17 \pm 0.01$ & $0.95 \pm 0.10$ & $2.4 \times 10^{-4}$ & $2.7 \times 10^{-3}$ \\
\hline HWG & 700 & 22.4 & $3.4 \pm 1.0$ & $0.45 \pm 0.05$ & $1.07 \pm 0.24$ & 0.3 & 1.43 \\
\hline HWG & 750 & 22.0 & $3.2 \pm 1.5$ & $1.13 \pm 0.50$ & $1.13 \pm 0.26$ & 2.2 & 3.24 \\
\hline HWG & 800 & 33.5 & $5.2 \pm 3.7$ & $4.56 \pm 0.80$ & $1.60 \pm 0.73$ & 6.8 & 3.11 \\
\hline HWG & 880 & 48.5 & $5.3 \pm 2.5$ & $9.80 \pm 3.40$ & $1.39 \pm 0.40$ & 14.0 & 3.09 \\
\hline $\mathrm{HWG}^{\mathrm{a}}$ & 890 & - & $6.0 \pm 3.0$ & $3.00 \pm 1.10$ & $1.40 \pm 0.30$ & 5.2 & 4.06 \\
\hline $\mathrm{FC}^{\mathrm{b}}$ & 880 & - & $8.3 \pm 3.5$ & $1.30 \pm 0.80$ & $1.95 \pm 0.25$ & 0.9 & 1.67 \\
\hline $\mathrm{FC}^{\mathrm{b}}$ & 880 & - & $7.8 \pm 2.7$ & $3.30 \pm 1.40$ & $1.95 \pm 0.25$ & 2.8 & 1.98 \\
\hline $\mathrm{FC}^{\mathrm{b}}$ & 1050 & - & $12.8 \pm 4.1$ & $9.40 \pm 1.40$ & $2.18 \pm 0.35$ & 9.8 & 3.08 \\
\hline
\end{tabular}

apreviously published data for HWG aerosol CVD [6], breviously published data for ferrocene aerosol CVD [24].

higher than $T_{\text {set }}$, which ranged from 550 to $800{ }^{\circ} \mathrm{C}$ at $50{ }^{\circ} \mathrm{C}$ intervals. The $\mathrm{CO}_{2}$ concentration was kept constant at $1300 \mathrm{ppm}$. The wire current of the HWG, affecting the catalyst number concentration through the evaporation rate, was kept constant at $2.7 \mathrm{~A}$. In addition, a benchmark sample was synthesized under previously optimized conditions at $880{ }^{\circ} \mathrm{C}$ with the introduction of $1500 \mathrm{ppm} \mathrm{CO}_{2}$. The SWCNTs were collected from the gas phase by filtering the flow at the reactor outlet through $10 \mathrm{~mm}$ diameter nitrocellulose disk filters (Millipore, HAWP, $0.45 \mu \mathrm{m}$ pore diameter). In addition to the HWG samples produced in this contribution, a set of data from similarly fabricated films reported earlier was included in comparisons of the film properties $[6,24]$. The synthesis parameters along with the SWCNT and bundle characteristics are listed for all of the samples in Table 1.

\section{Characterization}

The as-deposited SWCNT networks were press transferred $[6,16]$ from the low adhesion filters onto silicon or aluminium substrates for scanning electron microscope observation (SEM, JEOL JSM-7500FA, Japan) used to measure the SWCNT bundle lengths ( $\left.L_{\text {bundle }}\right)$. Similarly, SWCNT networks were transferred onto optically transparent $1 \mathrm{~mm}$ thick quartz substrates (HQS300, Heraeus) for Raman spectroscopy (LabRAM, HORIBA JobinYvon, France) utilizing a HeNe laser source of $632.82 \mathrm{~nm}(1.96 \mathrm{eV})$, and for UV-vis-NIR absorption spectroscopy (Perkin-Elmer Lambda 950) used to determine the SWCNT diameters $\left(d_{\text {tube }}\right)$. For high-resolution transmission electron microscope observation (HRTEM, double aberration-corrected JEOL JEM-2200FS) of the SWCNT bundle diameters $\left(d_{\text {bundle }}\right)$, a similar dry-transfer approach was implemented. Copper grids with holey-carbon coating were manually pressed against quartz substrates with the SWCNT networks, transferring a near-monolayer of SWCNTs onto the grids. The sheet resistances $\left(R_{\mathrm{S}}\right)$ were recorded with a four-point probe and a RM3-AR Test Meter $(60 \pm 5 \mathrm{~g}$ loading, Jandel Engineering, UK) from the SWCNT networks transferred onto quartz substrates.

\section{Results}

Varying the synthesis temperature $\left(T_{\text {set }}\right)$ resulted in major changes in the overall network and bundle characteristics of the as-prepared SWCNTs, as was observed by SEM and TEM. The overall amount of amorphous impurities in the SWCNT networks reduced dramatically with increasing $T_{\text {set }}$, as can be clearly observed in Figure 1 . At $T_{\text {set }}=650{ }^{\circ} \mathrm{C}$, the SWCNT networks were covered under a nearly continuous layer of amorphous carbonaceous material. At lower $T_{\text {set }}$ 's of 550 and $600{ }^{\circ} \mathrm{C}$, the SWCNT networks were too sparse to form continuous areas, or to even be clearly visible in SEM. Even so, TEM observations revealed the existence of short $(<100 \mathrm{~nm})$ SWCNTs embedded in an apparently amorphous carbon sheet, as shown in Figure 2. The relative amount of this amorphous material visibly reduced as $T_{\text {set }}$ was increased to $700{ }^{\circ} \mathrm{C}$, and the bundles were also much longer $\left(L_{\text {bundle }} 700{ }^{\circ} \mathrm{C}=0.45\right.$ versus $\left.L_{\text {bundle }} 650{ }^{\circ} \mathrm{C}=0.17 \mu \mathrm{m}\right)$. The same trend was found to hold at higher $T_{\text {set }}$ as well; $L_{\text {bundle }} 750{ }^{\circ} \mathrm{C}=1.13 \mu \mathrm{m}, L_{\text {bundle }} 800{ }^{\circ} \mathrm{C}=$ $4.56 \mu \mathrm{m}$, and $L_{\text {bundle }} 880{ }^{\circ} \mathrm{C}=9.80 \mu \mathrm{m}$. The corresponding $L_{\text {bundle }}$ distributions are presented in Figure $3 \mathrm{a}$. Both the decrease in the relative amount of amorphous material and the increase in $L_{\text {bundle }}$ were expected, since the catalytic activity of iron nanoparticles and diffusion rate of carbon are both more suitable for SWCNT production at higher temperatures $[25,26]$. This was also clearly evidenced by an increase in the reactor output concentration as confirmed with the DMA measurements: the number concentration $(N C)$ increased steadily from 

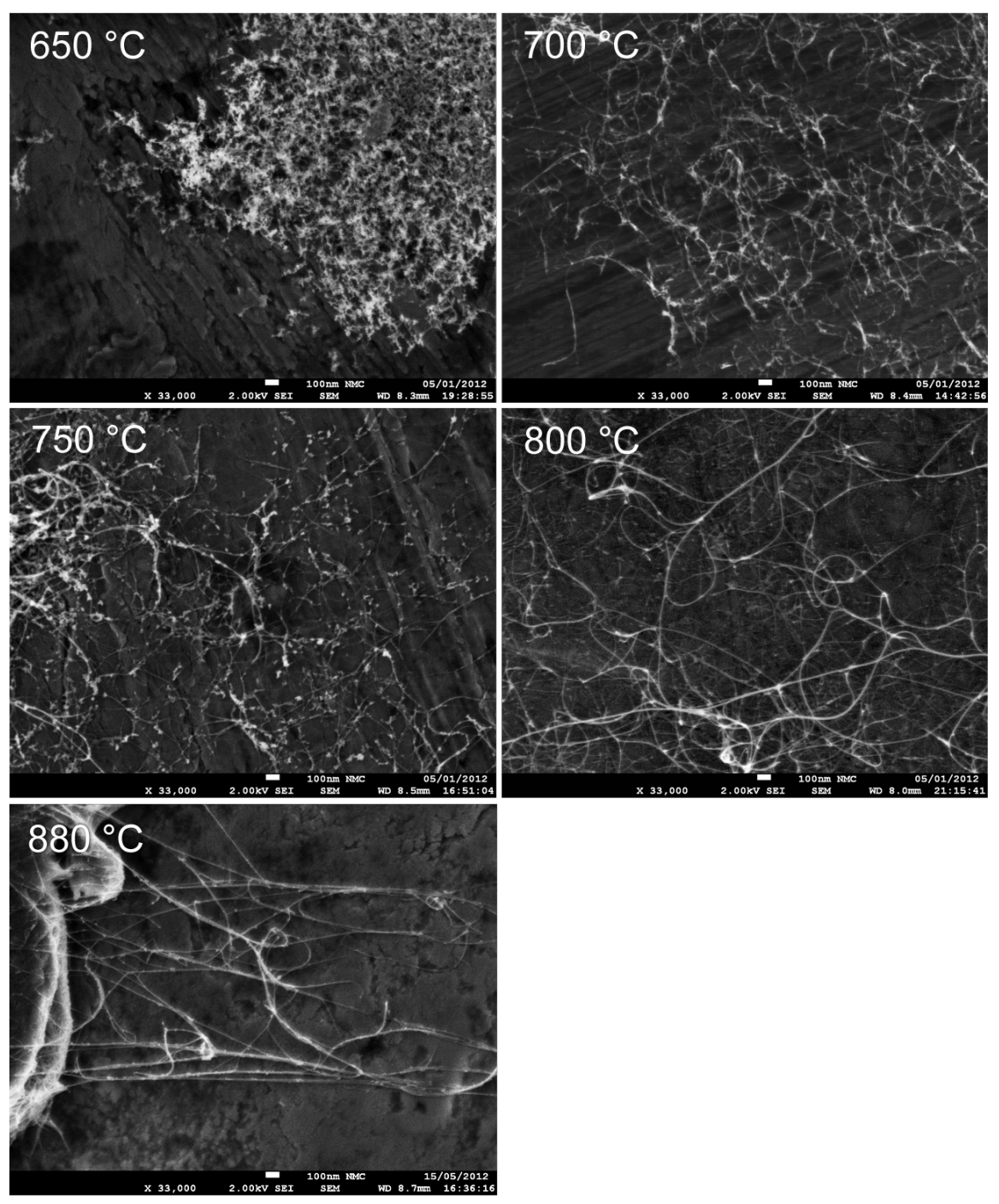

Figure 1: SEM images of as-prepared SWCNT networks dry-transferred onto the aluminium substrate. From top left, synthesis temperature increases from 650 to $880^{\circ} \mathrm{C}$ and the average bundle length from $0.17 \pm 0.01$ to $9.80 \pm 3.40 \mu \mathrm{m}$.

$N C_{650}{ }^{\circ} \mathrm{C}=6 \times 10^{5} \mathrm{~cm}^{-3}$ at $T_{\text {set }}=650{ }^{\circ} \mathrm{C}$, with the corresponding geometric mean diameter $G M D_{650}{ }^{\circ} \mathrm{C}=45 \mathrm{~nm}$, reaching $N C_{800}{ }^{\circ} \mathrm{C}=2 \times 10^{7} \mathrm{~cm}^{-3}$ and $G M D_{800}{ }^{\circ} \mathrm{C}=55 \mathrm{~nm}$ at $T_{\text {set }}=800^{\circ} \mathrm{C}$. TEM observations also revealed an increase in the bundle diameters $d_{\text {bundle }}$ with increasing $T_{\text {set }}$, as depicted by the $d_{\text {bundle }}$ distributions shown in Figure $3 \mathrm{~b}$.

Furthermore, SWCNTs synthesized at $T_{\text {set }}<650{ }^{\circ} \mathrm{C}$ were less able to withstand the electron irradiation dose in the TEM, disintegrating at magnifications higher than $600 \mathrm{k}$. Their graphitization level, e.g., the crystallinity of the hexagonal carbon lattice, was thus likely poor, with the tubes containing a high concentration of defects. Therefore, in order to judge the relative SWCNT quality, we utilized resonant Raman spectroscopy. For us the most interesting features in the Raman spectra were the intensities of the $\mathrm{G}$ and $\mathrm{D}$ bands, along with the radial breathing modes (RBM). In graphitic carbon, the $G$ band $\left(\sim 1580 \mathrm{~cm}^{-1}\right)$ corresponds to planar vibrations of carbon atoms, while the $\mathrm{D}$ band $\left(\sim 1350 \mathrm{~cm}^{-1}\right)$ is sensitive to structural defects and impurities such as amorphous carbon and vacancies in the $\mathrm{sp}^{2}$-hybridized carbon lattice [27]. Therefore, the ratio of the intensities of the $\mathrm{G}$ and $\mathrm{D}$ bands $\left(I_{\mathrm{G}} / I_{\mathrm{D}}\right)$ in the Raman spectra was used as a measure of the material graphitization level as a whole. RBMs (about 100-350 $\mathrm{cm}^{-1}$ ), on the other hand, correspond to the radial expansion-contraction of the SWCNTs, and their frequencies $\omega_{\mathrm{RBM}}$ are correlated with SWCNT diameters $d_{\text {tube by }}$

$$
\omega_{\mathrm{RBM}}=\frac{A}{d_{\text {tube }}}+B
$$




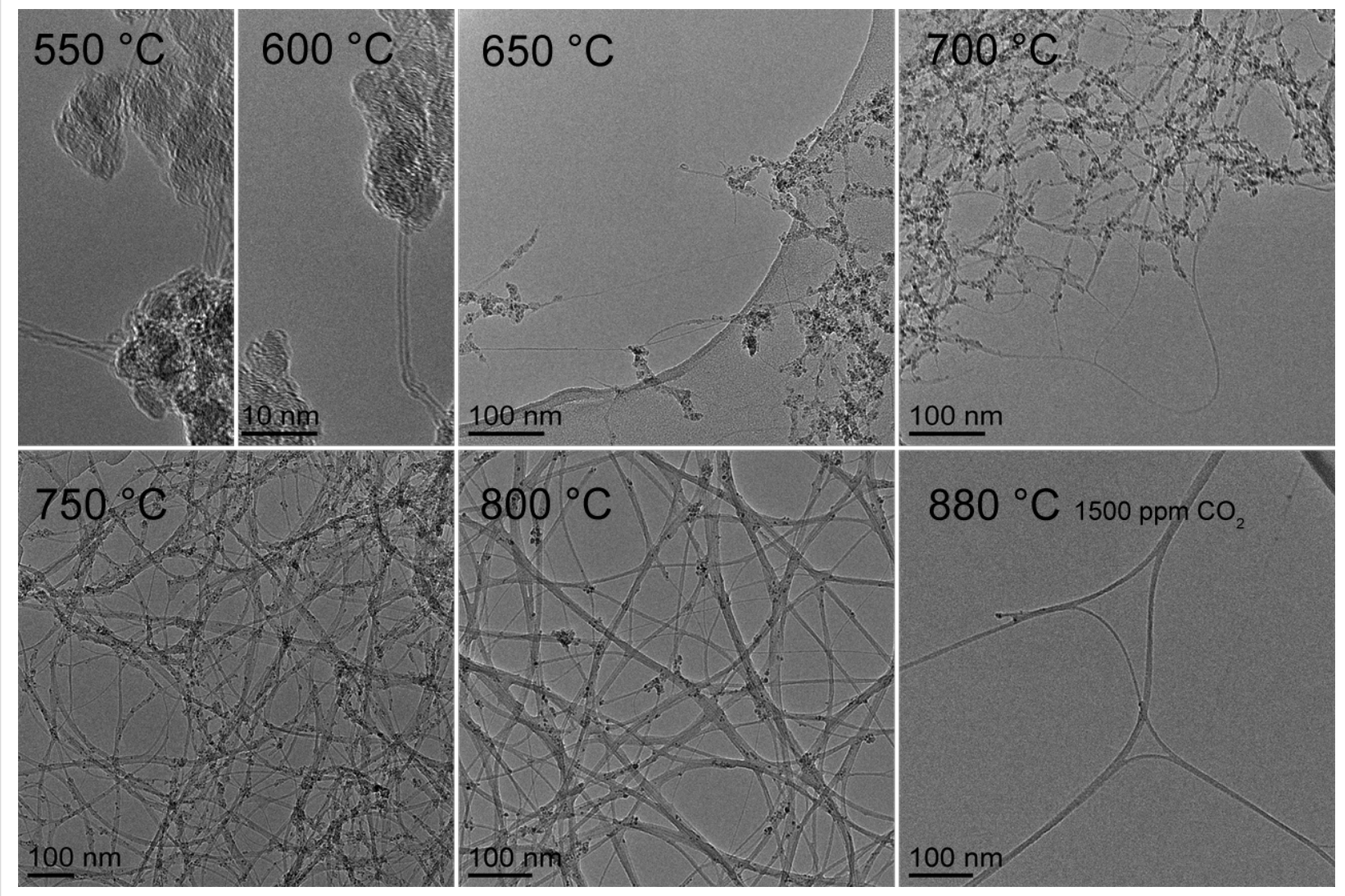

Figure 2: TEM micrographs of the as-produced SWCNTs. The synthesis conditions and corresponding bundle diameters are $550^{\circ} \mathrm{C}, 1300 \mathrm{ppm}, \mathrm{N} / \mathrm{A}$; $600{ }^{\circ} \mathrm{C}, 1300 \mathrm{ppm}, \mathrm{N} / \mathrm{A} ; 650^{\circ} \mathrm{C}, 1300 \mathrm{ppm}, 3.1 \pm 1.0 \mathrm{~nm} ; 700^{\circ} \mathrm{C}, 1300 \mathrm{ppm}, 3.4 \pm 1.0 \mathrm{~nm} ; 750^{\circ} \mathrm{C}, 1300 \mathrm{ppm}, 3.2 \pm 1.5 \mathrm{~nm} ; 800{ }^{\circ} \mathrm{C}, 1300 \mathrm{ppm}$, $5.2 \pm 3.7 \mathrm{~nm}$; and $880^{\circ} \mathrm{C}, 1500 \mathrm{ppm}, 5.3 \pm 2.5 \mathrm{~nm}$. Note that the $880^{\circ} \mathrm{C}$ sample was collected electrostatically, resulting in a lower SWCNT density on the TEM grid.

(a)

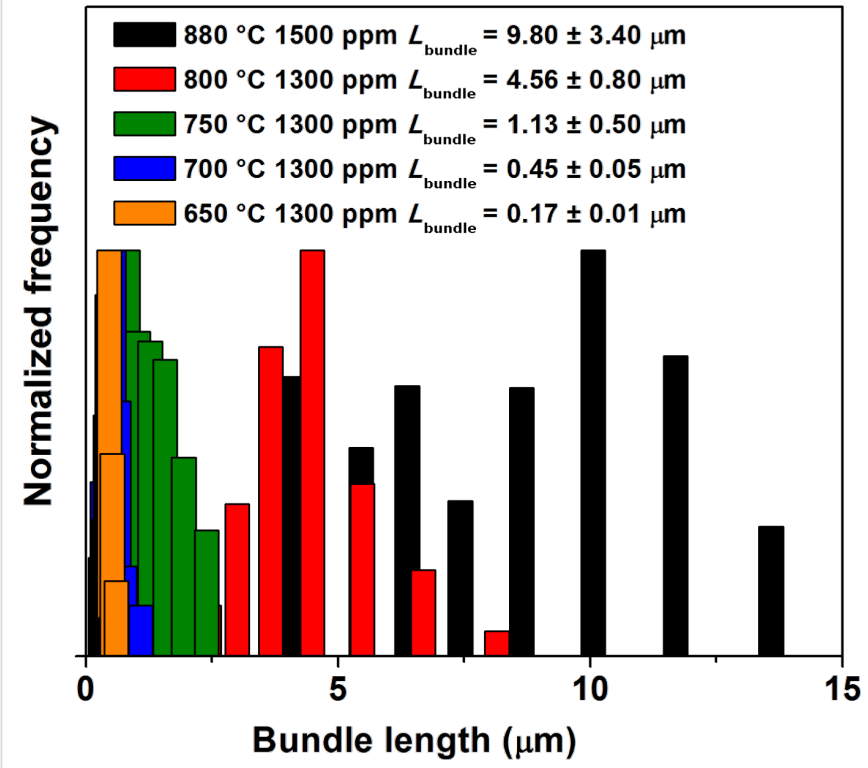

(b)

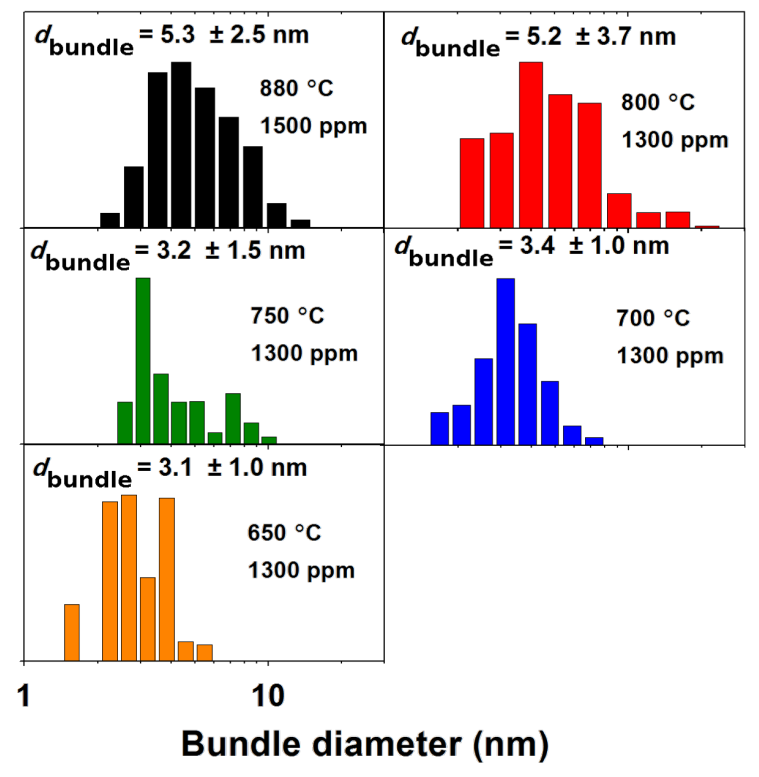

Figure 3: (a) Bundle length statistics measured from SEM images, and (b) bundle diameter statistics from TEM micrographs. 
where $A$ and $B$ are determined experimentally [28]. Here, parameter values $A=248 \mathrm{~cm}^{-1} \mathrm{~nm}$ and $B=0 \mathrm{~cm}^{-1}$ were used to infer the diameters of SWCNTs in resonance with the laser excitation. These Raman features are shown in Figure 4.

The $I_{\mathrm{G}} / I_{\mathrm{D}}$ ratio for SWCNTs synthesized at $T_{\mathrm{set}}=550$ and $600{ }^{\circ} \mathrm{C}$ was roughly 5 , which indicates either a very high defect density or a high impurity level. Certainly, the D band originates partly from the amorphous impurities on the samples, which were clearly seen by SEM and TEM. Regardless of the exact origin of the $\mathrm{D}$ band in our samples, a comparison of the $I_{\mathrm{G}} / I_{\mathrm{D}}$ ratio of samples from $T_{\mathrm{set}}=650-880{ }^{\circ} \mathrm{C}$ revealed an increase of $I_{\mathrm{G}} / I_{\mathrm{D}}$ from $5.2\left(550{ }^{\circ} \mathrm{C}\right)$ to $48.4\left(880^{\circ} \mathrm{C}\right)$. This indicates a substantial enhancement of sample quality with increasing $T_{\text {set }}$ (cf. Figure 2 and Figure 4 inset).

In addition to SWCNT bundle characteristics and defect density, the SWCNT chirality distribution and diameters $\left(d_{\text {tube }}\right)$ can contribute both to conductivity and light-absorption prop- erties [27,29]. UV-vis-NIR absorption spectroscopy is a versatile tool that can be used to define both $d_{\text {tube }}$ and, to a limited extent, metallicity [30]. The fitting of semiconducting ( $E_{11}$ and $\left.E_{22}\right)$ and metallic $\left(M_{11}\right)$ optical-transition peaks to the absorption spectra shown in Figure 5 resulted in the corresponding $d_{\text {tube }}$ distributions plotted below the spectra. The mean $d_{\text {tube }}$ increased with $T_{\text {set }}$ from $0.95 \mathrm{~nm}\left(650^{\circ} \mathrm{C}\right)$ to $1.60 \mathrm{~nm}\left(800^{\circ} \mathrm{C}\right)$. However, the benchmark sample with $T_{\text {set }}=880{ }^{\circ} \mathrm{C}$ had a slightly smaller $d_{\text {tube }}$ at $1.39 \mathrm{~nm}$.

Finally, we consider the optoelectronic properties of the films. For networks that share the same total concentration of carbon (and thus absorbance) and general morphology, it was previously shown that the number of bundle-bundle contacts scales inversely with the average bundle length [24]. Since the network resistance scales linearly with the number of contacts, conductance thus scales linearly with the average bundle length. The absorbance $(A)$ and conductance $\left(\sigma_{\mathrm{DC}}\right)$ can be linked by the so-called figure of merit $K[6]$

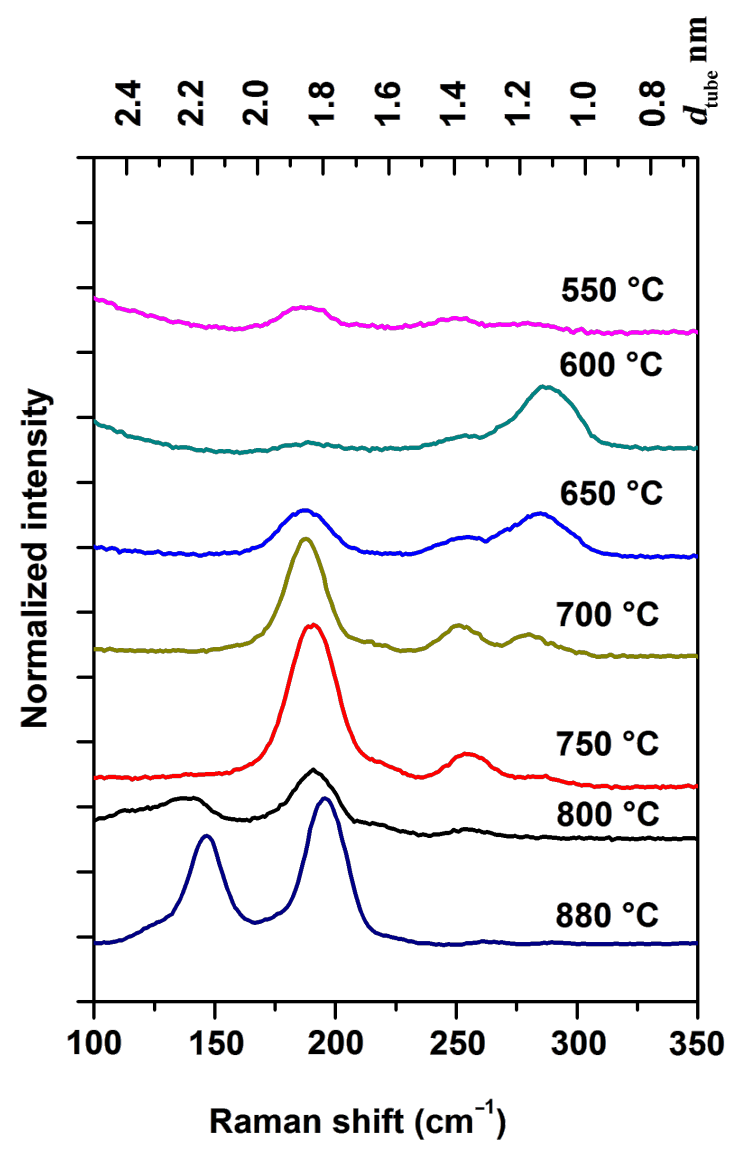

\section{$1300 \mathrm{ppm} \mathrm{CO}$}

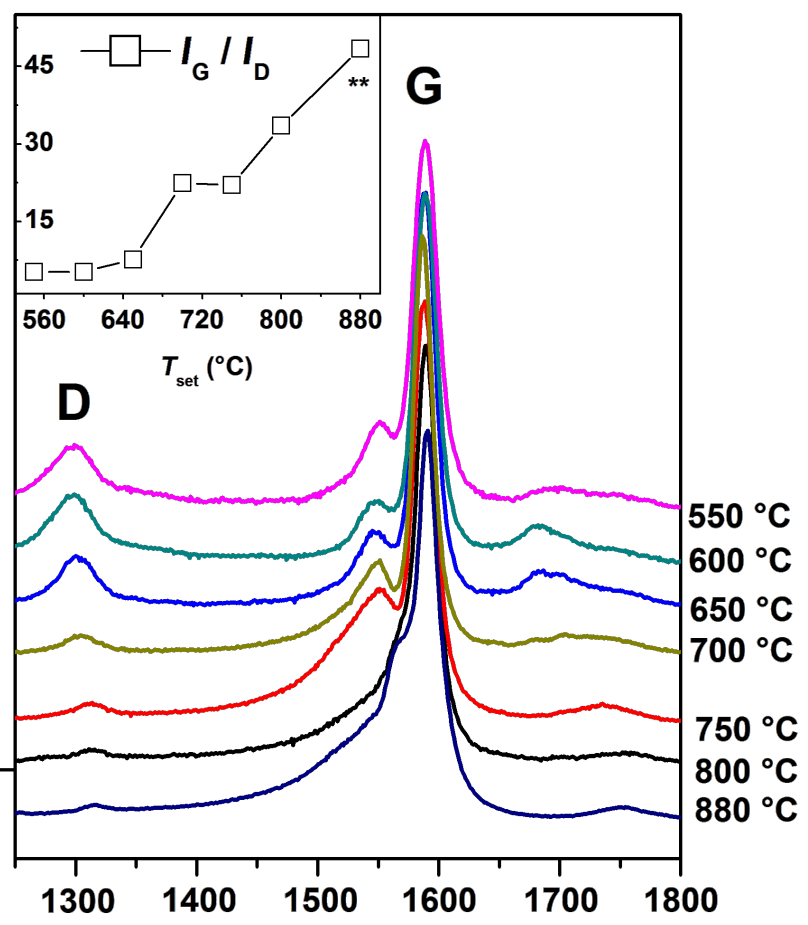

Raman shift $\left(\mathrm{cm}^{-1}\right)$

Figure 4: RBM modes (left) and D and G bands (right) of resonant Raman spectra recorded from SWCNTs synthesized under different temperature conditions $\left(550-880^{\circ} \mathrm{C}\right)$. The inset plots the ratio of $G$ and $D$ band intensities $\left(I_{G} / I_{D}\right)$ with increasing $T_{\text {set. }}$ Laser wavelength of the Raman system was $632.82 \mathrm{~nm}(1.96 \mathrm{eV})$. 

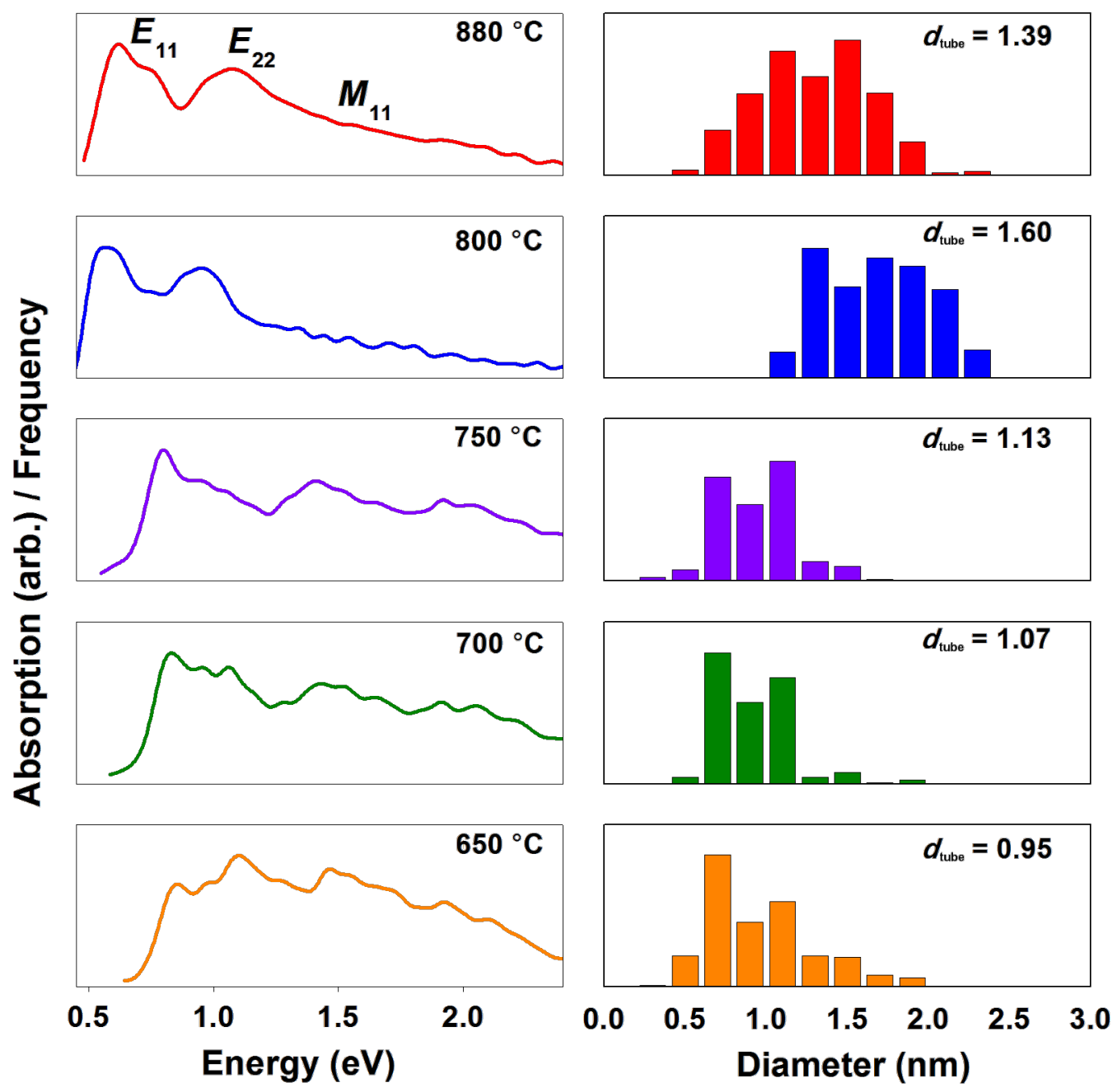

Figure 5: UV-vis-NIR absorption spectra (left) from the SWCNTs synthesized under different temperature conditions $\left(650-880{ }^{\circ} \mathrm{C}\right)$ and the SWCNT diameter distributions (right) fitted to each spectrum.

$$
K=\frac{1}{-R_{\mathrm{s}} \ln [T(\lambda)]}=\frac{\sigma_{\mathrm{DC}}}{A} \propto L_{\mathrm{b}},
$$

where $R_{\mathrm{S}}$ is the sheet resistance and $T(\lambda)$ (later simply $T$ ) the transmittance measured at the middle of the visible spectrum $(\lambda=550 \mathrm{~nm}$, or $2.3 \mathrm{eV})$. The UV-vis-NIR absorption spectra and four-point sheet resistance values shown in Table 1 were used to calculate the corresponding $K$ 's shown in Figure 6. The solid curves represent previously published data for SWCNTs synthesized both by using a ferrocene [6] and a HWG aerosol CVD [24], while the scattered data represent the current study. The higher the figure of merit $K$ is, the further left are the data situated in the plot. Referring to Equation 2, we may distinguish two distinct populations of SWCNTs when $K$ is plotted as a function of $L_{\text {bundle }}$, both following linear regression but with diverging slopes (Figure 7a). The continuous black line corre- sponds to SWCNTs from HWG aerosol CVD, while the blue dashed line corresponds to ferrocene aerosol CVD SWCNTs.

To elucidate contributions to film performance caused by nongeometric factors (i.e., junction resistances or contact barriers), the data can be normalized by eliminating the contributions of variations in bundle diameter and length.

According to the Beer-Lambert law, for films of a given thickness $(d)$, absorbance $(A)$ depends linearly on the concentration (C) of absorbers in the film (in our case carbon, $C_{\text {carbon }}$ ). In carbon nanotube thin films, the carbon is distributed in the form of carbon nanotubes with an average tube length and diameter $\left(d_{\text {tube }}\right)$. Due to van der Waals interactions, the carbon nanotubes form regular bundles with an average length ( $\left.L_{\text {bundle }}\right)$ and average diameter ( $\left.d_{\text {bundle }}\right)$. We assume that the shape of a bundle is approximately independent of its constituent 


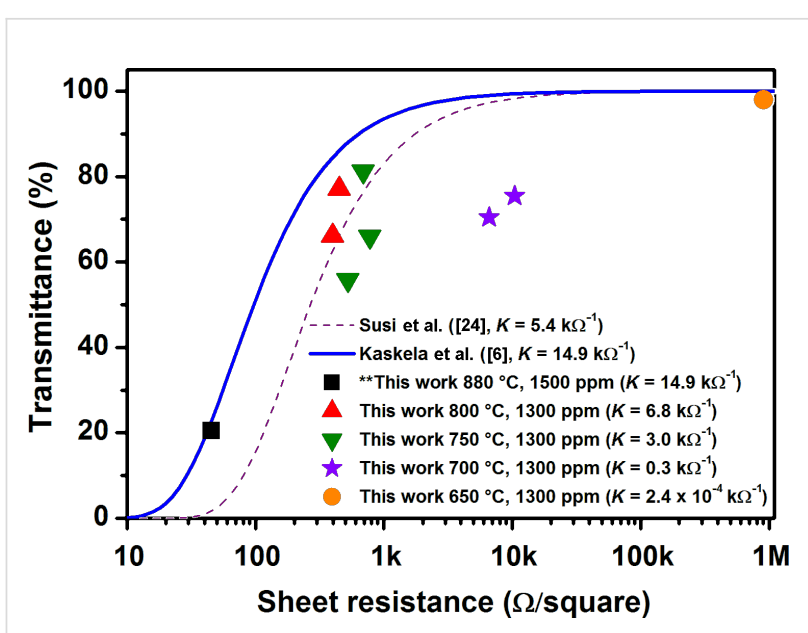

Figure 6: Comparison of sheet resistance versus optical transparency (at $550 \mathrm{~nm}$ ) of SWCNTs synthesized at different temperatures $\left(650-880^{\circ} \mathrm{C}\right)$. The black square represents the benchmark sample $\left(880^{\circ} \mathrm{C}\right)$, red upright triangles SWCNTs from $800{ }^{\circ} \mathrm{C}$, green downright triangles SWCNTs from $7500^{\circ} \mathrm{C}$, purple stars SWCNTs from $700^{\circ} \mathrm{C}$ and the orange circle SWCNTs from $650^{\circ} \mathrm{C}$. The blue solid line and the purple dashed line represent the literature data used for comparisons.

nanotubes, meaning that the length of a bundle is determined by the length of its nanotubes, and its diameter by the diameter of its nanotubes $\left(d_{\text {tube }}\right)$ and the degree of bundling caused by the synthesis process.

The total concentration of carbon on a given area (or volume) may then be expressed with the average areal (or volumetric) density ( $\left.\rho_{\text {bundle }}\right)$, the average length $\left(L_{\text {bundle }}\right)$ and the average diameter of bundles ( $\left.d_{\text {bundle }}\right)$. Typically the junction resistance, $R_{\mathrm{J}}$, is thought to be much higher than the intratube (or intra- bundle) resistance, $R_{\mathrm{I}}$, that is, $R_{\mathrm{J}}>>R_{\mathrm{I}}$. Thus, the conductance of a film $\left(\sigma_{\mathrm{DC}}\right)$ is expected to depend on the geometric parameters, both because shorter bundles will result in more high-resistance junctions per unit length, and possibly because the bundle geometry alters the resistive properties of the junctions.

Given that the average bundle length, $L_{\text {bundle, }}$ and the average number density of bundles in the network, $\rho_{\text {bundle }}$, remain constant, the average bundle diameter, $d_{\text {bundle }}$, dictates the total concentration of carbon. This is best depicted by the illustration in Figure 8, graphically relating $C_{\text {carbon }}$ and $d_{\text {bundle }}$.

Obviously, $C_{\text {carbon }}$ increases linearly with the average number of individual SWCNTs in bundles $(N)$, which in the two-dimensional illustration depends linearly on $d_{\text {bundle. In reality, of }}$ course, the bundles are not flat but three-dimensional, and on average, circular in cross section. In three dimensions, we can evaluate $N$, and thus the total concentration of carbon, as

$$
C_{\text {carbon }} \propto N=\frac{\pi}{\frac{\pi}{2}-\tan ^{-1} \sqrt{1-\frac{2 d_{\text {tube }}}{d_{\text {bundle }}}}} .
$$

Equation 3 gives the average number of tubes per bundle in the case of circular bundles, containing more than three individual tubes. In our case, the average bundle diameters are systematically more than $3 \mathrm{~nm}$ (and $N>5$ ), and thus, Equation 3 gives a good approximation for $N$. As was discussed earlier, absorbance is linked to the total number of individual absorbers and to $N$ as well. Therefore it is justified to interpret $N$ as a measure of absorbance induced purely by geometric effects, i.e., changes in bundle diameters.
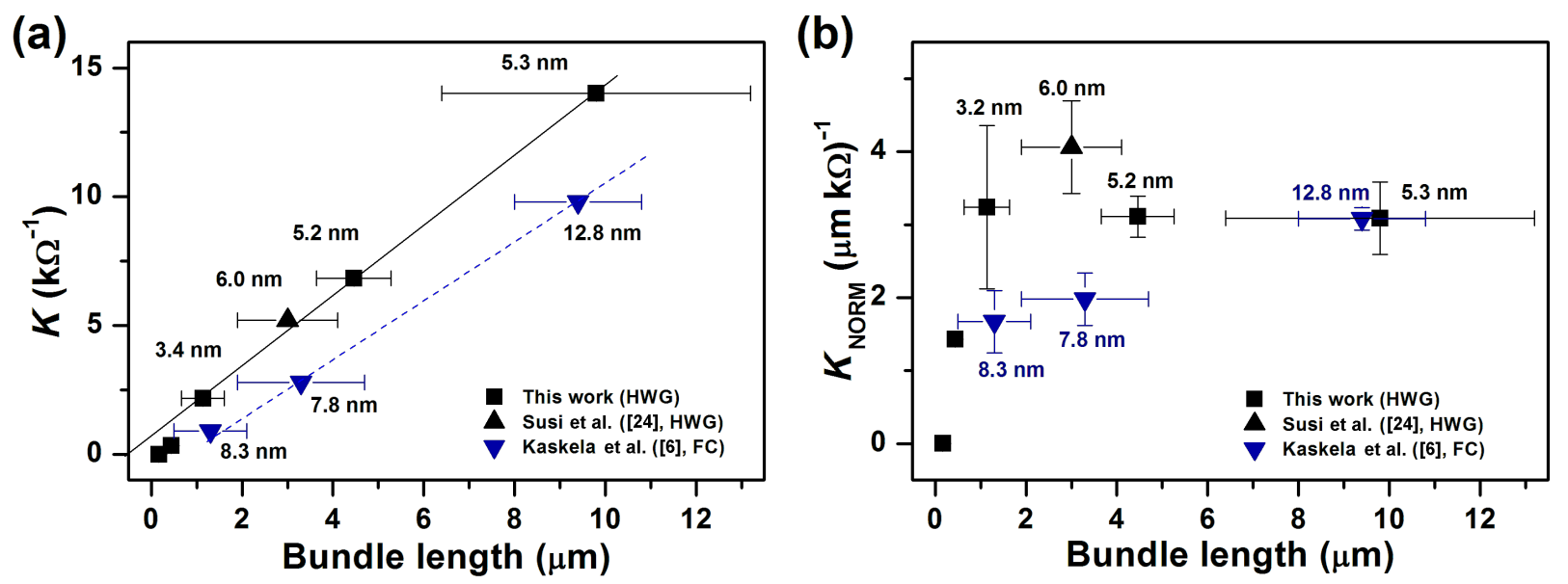

Figure 7: (a) The figure of merit $K$ versus bundle length. A linear dependence of $K$ on $L_{\text {bundle }}$ is observed, as expected from geometric scaling arguments combined with the Beer-Lambert law. The higher the $K$, the better the optoelectronic performance. (b) Normalized figure of merit $K_{\mathrm{NORM}}$ versus $L_{\text {bundle. }}$ The apparent difference between the two datasets (black and blue) is greatly reduced. 


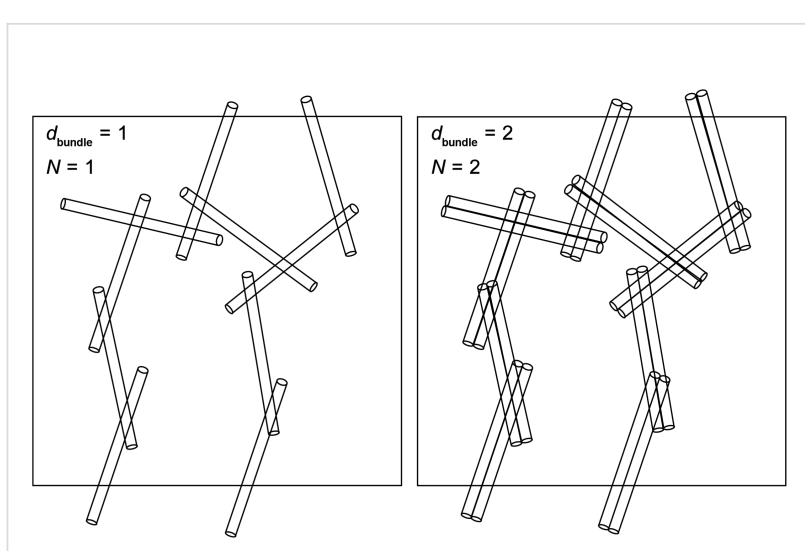

Figure 8: An illustration to clarify how the total concentration of carbon depends on bundle diameter for a given network morphology. Note that the number of bundle-bundle junctions is equal in both cases.

Hence, for a set number of bundle-bundle contacts, the concentration of absorbers $\left(C_{\text {carbon }}\right)$, and thus film absorbance, scales linearly with the average number of individual SWCNTs in bundles $(N)$. This can in turn be estimated from the average bundle diameter $d_{\text {bundle }}$ using simple arguments introduced above. Therefore, we can normalize $K$ taking into account both of these purely geometric effects, resulting in

$$
K_{\mathrm{NORM}}=\left|\frac{K}{L_{\mathrm{b}}\left[\ln \left(N^{-1}\right)\right]}\right|
$$

Figure $7 \mathrm{~b}$ plots $K_{\mathrm{NORM}}$ as a function of $L_{\text {bundle }}$, chosen as the $x$-axis since it is the most prominent factor defining the value of $K$. An immediate observation is that both $K$ and $K_{\text {NORM }}$ fall to zero slightly before $L_{\text {bundle }}$ approaches zero. The physical interpretation of such behavior is the existence of a percolation threshold (e.g., the threshold where the long range connectivity of remote parts in a random network is lost), which becomes evident when $L_{\text {bundle }}$ is very small. At the edge of the threshold, the conductivity of the network rapidly collapses.

Provided $L_{\text {bundle }}$ strictly dictates the geometric scaling of conductance and $d_{\text {bundle }}$ the geometric scaling of absorbance, the normalized values should lie on a vertical line, $K_{\mathrm{NORM}}=$ constant. Indeed, besides the points close to the percolation threshold $\left(L_{\text {bundle }}<1 \mu \mathrm{m}\right)$, the normalized data are around $K_{\mathrm{NORM}}=3 \pm 1 \mu \mathrm{m}^{-1} \cdot \mathrm{k} \Omega^{-1}$. Some small variation does remain: ferrocene aerosol CVD data (blue downward triangles) generally fall slightly below the average, while HWG aerosol CVD data (black squares and an upward triangle) appear slightly above the average, although in a much less pronounced manner than in the non-normalized data in Figure 7a. This suggests that the difference between the two datasets in Figure 7a is mostly due to the enhanced absorbance of the thicker ferrocene reactor bundles.

\section{Discussion}

So far only the effect of the average bundle diameter on the absorbance has been considered. As was discussed, this entirely geometric effect can be taken into account by the normalization steps. Thus, any remaining effects are likely electronic in nature, possibly caused by modifications of the resistive junctions. The bundle diameters were effectively tuned by varying the synthesis temperature, which resulted in different aerosol number concentrations in the reactor. Larger diameter bundles are expected to form at higher number concentrations, which was indeed observed by comparing the reactor outlet aerosol concentrations with the average bundle diameters: higher concentrations resulted in larger bundles. Obviously, no significant correlation between the average bundle diameter and $K_{\text {NORM }}$ can be observed in Figure $7 \mathrm{~b}$. Thus, it seems that $d_{\text {bundle }}$ is responsible for changes in the optoelectronic performance of the films only as far as absorption is concerned.

This contradicts earlier work by Nirmalraj et al. [12], who used contact mode atomic force microscopy to determine the junction resistances of individual SWCNTs and bundles. Their data showed an approximately 10-fold increase in the junction resistances when the average bundle diameter increased from $3.5 \pm 1.5$ to $10.5 \pm 4.9 \mathrm{~nm}$. For such a large increase in junction resistances, the corresponding change in $K$ and $K_{\text {NORM }}$ would be approximately 10 - and 20 -fold, respectively. Our data shows practically no effect for a similar change of $d_{\text {bundle }}$, as is evident in Figure 7a and Figure 7b. More work on direct measurement of the bundle-bundle contact resistances is clearly needed to resolve these discrepancies.

The SWCNT diameter $d_{\text {tube }}$ modifies the electronic transitions of SWCNTs, and thus impacts not only the contact and Schottky barriers [31], but also the light-absorption properties $[27,29]$. SWCNTs of small $d_{\text {tube }}$ have their first-order metallictransition peaks $\left(M_{11}\right)$ located around $550 \mathrm{~nm}(2.3 \mathrm{eV})$, whereas for larger $d_{\text {tube }}$ SWCNTs the peaks are shifted to lower energies (higher wavelengths). This slightly lowers the absorbance at the reference wavelength. Furthermore, contact and Schottky barriers are larger for SWCNTs of smaller $d_{\text {tube }}$. Therefore, due to relatively higher absorption, and contact and Schottky barriers, films comprising smaller $d_{\text {tube }}$ SWCNTs could be expected to exhibit lower optoelectronic performances in comparison with larger $d_{\text {tube }}$ ones. However, in our samples these factors are clearly not important, and no correlation is observed. As far as $K_{\text {NORM }}$ is considered, HWG aerosol CVD SWCNTs of larger $d_{\text {tube }}(1.39-1.60 \mathrm{~nm})$ perform equally well as those 
with smaller $d_{\text {tube }}(1.13 \mathrm{~nm})$. Furthermore, ferrocene aerosol CVD SWCNTs (blue downward triangles) have generally much larger $d_{\text {tube }}(1.9-2.2 \mathrm{~nm})$ than the HWG aerosol CVD ones (black squares and triangle). Thus, in this comparison, they might be expected to exhibit the highest optoelectronic performance. In reality, however, the opposite is observed, as is evident in Figure $7 \mathrm{~b}$. Thus, $d_{\text {tube }}$ cannot explain the observed variation in $K_{\mathrm{NORM}}$.

Besides $d_{\text {tube }}$, also the defect density and the amount of amorphous impurities were observed to vary in our samples. Ideally, due to the $\mathrm{sp}^{2}$-hybridized tubular carbon lattice structure, SWCNTs are ballistic electrical conductors [32]. In reality, however, both lattice defects and amorphous impurities are always present to some degree. In this study, the resonant Raman intensity ratios $I_{\mathrm{G}} / I_{\mathrm{D}}$ were used to gauge both the SWCNT lattice quality and the relative amount of amorphous impurities in the samples. At low $T_{\text {set }}\left(650-700^{\circ} \mathrm{C}\right)$ conditions, the samples were seemingly contaminated by nongraphitized carbon; while at high $T_{\text {set }}\left(750-880^{\circ} \mathrm{C}\right)$ they were much cleaner (cf. Figure 1 and Figure 2). Simultaneously, alongside increasing $T_{\text {set }}$, the $I_{\mathrm{G}} / I_{\mathrm{D}}$ ratio rises from 5.2 to 48.5 (Figure 4 inset), confirming either better SWCNT lattice crystallinity or decreasing amount of amorphous carbon, or possibly both. Even though this increase was significant, the $I_{\mathrm{G}} / I_{\mathrm{D}}$ ratios were not predictive for the value of $K_{\mathrm{NORM}}$ (cf. Figure 4 inset and Figure $7 \mathrm{~b}$ ). In fact, $K_{\text {NORM }}$ did not show significant changes over the interval from $T_{\text {set }}=750{ }^{\circ} \mathrm{C}\left(I_{\mathrm{G}} / I_{\mathrm{D}}=22.0\right)$ to $T_{\text {set }}=$ $880{ }^{\circ} \mathrm{C}\left(I_{\mathrm{G}} / I_{\mathrm{D}}=48.5\right)$, as should be expected if the defect density or amount of amorphous impurities were significant contributors to the performance of the films.

Thus, it seems that neither the average tube diameter $d_{\text {tube }}$ nor the defect density or amount of amorphous impurities impact the overall optoelectronic performance of the networks significantly. A simple explanation could lie in the very nature of a random SWCNT network, which consists of an enormous number of parallel and series resistors, each resistive component being a single SWCNT, an SWCNT bundle, or a junction. The junction resistances are thought to be on the order of several kilo-ohms, and possibly higher [12], while intratube or -bundle resistances are much lower. Thus, as was discussed before, to a good approximation, the system can be considered to be a resistor network comprising only the junctions. Therefore small or even moderate modifications in the average intrabundle conductivity would not alter the overall network conduction dramatically. Contact and Schottky barriers between SWCNTs, on the other hand, are certainly in principle affected by $d_{\text {tube }}$. However, where contact barriers are concerned, the distances between individual SWCNTs and bundles likely affect the actual contact resistances much more than the contact barriers alone. In this regard we note that densification by using ethanol is known to reduce the sheet resistance of pristine SWCNT films by about an order of magnitude [6], likely by bringing the network elements closer to each other. Finally, Schottky barriers may not necessarily be important in films consisting of both metallic and semiconducting tubes, since there are always plenty of metallic pathways available for conduction in a dense enough SWCNT network [8]. Chargetransfer doping by acid functionalization [33,34], on the other hand, can affect either the electronic nature of individual tubes [6], barriers between bundles, or both. Again, further work on measuring individual contacts is called for.

\section{Conclusion}

The influence of SWCNT bundle characteristics on the optoelectronic performance of dry-deposited thin films was studied. Bundle length had a profound effect on SWCNT film conductivity, and thus on their performance. Bundle diameters had a lesser effect: thin films comprising larger diameter bundles performed worse than those with smaller diameter ones. However, our analysis indicates that this is due to the higher absorption of thicker bundles, since a geometric normalization of this contribution made the film performances independent of bundle diameter. Finally, neither the defect or impurity density, nor the individual SWCNT diameters affected the overall optoelectronic performances significantly, which thus seems to be best improved by simply increasing the bundle lengths. The bundle diameter, on the other hand, should be minimized, provided bundle lengths can be maximized simultaneously.

\section{Acknowledgements}

The authors would like to acknowledge support from the EU-FP7 NANODEVICE project (grant agreement no. CP-IP 211464-2), the Finnish Foundation for Technology Promotion, the Academy of Finland, the CNB-E project of the Aalto MIDE program, and the LiBaCAM project of TEKES. We also thank Heikki Pulkkinen for assistance in the HWG sample synthesis.

\section{References}

1. Hayamizu, Y.; Yamada, T.; Mizuno, K.; Davis, R. C.; Futaba, D. N.; Yumura, M.; Hata, K. Nat. Nanotechnol. 2008, 3, 289-294. doi:10.1038/nnano.2008.98

2. Kong, J.; Franklin, N. R.; Zhou, C.; Chapline, M. G.; Peng, S.; Cho, K.; Dai, H. Science 2000, 287, 622-625. doi:10.1126/science.287.5453.622

3. Collins, P. G.; Bradley, K.; Ishigami, M.; Zettl, A. Science 2000, 287, 1801-1804. doi:10.1126/science.287.5459.1801

4. Zhang, D.; Ryu, K.; Liu, X.; Polikarpov, E.; Ly, J.; Tompson, M. E.; Zhou, C. Nano Lett. 2006, 6, 1880-1886. doi:10.1021/nl0608543

5. Zhang, M.; Fang, S.; Zakhidov, A. A.; Lee, S. B.; Aliev, A. E.; Williams, C. D.; Atkinson, K. R.; Baughman, R. H. Science 2005, 309, 1215-1219. doi:10.1126/science.1115311 
6. Kaskela, A.; Nasibulin, A. G.; Timmermans, M. Y.; Aitchison, B.; Papadimitratos, A.; Tian, Y.; Zhu, Z.; Jiang, H.; Brown, D. P.; Zakhidov, A.; Kauppinen, E. I. Nano Lett. 2010, 10, 4349-4355. doi:10.1021/nl101680s

7. Jang, S.; Jang, H.; Lee, Y.; Suh, D.; Baik, S.; Hong, B. H.; Ahn, J.-H. Nanotechnology 2010, 21, 425201. doi:10.1088/0957-4484/21/42/425201

8. Sun, D.-m.; Timmermans, M. Y.; Tian, Y.; Nasibulin, A. G.; Kauppinen, E. I.; Kishimoto, S.; Mizutani, T.; Ohno, Y. Nat. Nanotechnol. 2011, 6, 156-161. doi:10.1038/nnano.2011.1

9. Futaba, D. N.; Hata, K.; Yamada, T.; Hiraoka, T.; Hayamizu, Y.; Kakudate, Y.; Tanaike, O.; Hatori, H.; Yumura, M.; lijima, S. Nat. Mater. 2006, 5, 987-994. doi:10.1038/nmat1782

10. Monthioux, M.; Smith, B. W.; Burteaux, B.; Claye, A.; Fischer, J. E.; Luzzi, D. E. Carbon 2001, 39, 1251-1272. doi:10.1016/S0008-6223(00)00249-9

11. Lu, K. L.; Lago, R. M.; Chen, Y. K.; Green, M. L. H.; Harris, P. J. F.; Tsang, S. C. Carbon 1996, 34, 814-816. doi:10.1016/0008-6223(96)89470-X

12. Nirmalraj, P. N.; Lyons, P. E.; De, S.; Coleman, J. N.; Boland, J. J. Nano Lett. 2009, 9, 3890-3895. doi:10.1021/nl9020914

13. Schrage, C.; Kaskel, S. ACS Appl. Mater. Interfaces 2009, 1, 1640-1644. doi:10.1021/am9002588

14. Hecht, D.; Hu, L.; Grüner, G. Appl. Phys. Lett. 2006, 89, 133112. doi:10.1063/1.2356999

15. Geng, H.-Z.; Lee, Y. H. Transparent Conducting Films by Using Carbon Nanotubes. In Nanoscale Phenomena; Tang, Z.; Sheng, P., Eds.; Springer: New York, USA, 2008; Vol. 2, pp 15-28. doi:10.1007/978-0-387-73048-6_3

16. Nasibulin, A. G.; Kaskela, A.; Mustonen, K.; Anisimov, A. S.; Ruiz, V.; Kivistö, S.; Rackauskas, S.; Timmermans, M. Y.; Pudas, M.; Aitchison, B.; Kauppinen, M.; Brown, D. P.; Okhotnikov, O. G.; Kauppinen, E. I. ACS Nano 2011, 5, 3214-3221. doi:10.1021/nn200338r

17. Zhou, Y.; Hu, L.; Grüner, G. Appl. Phys. Lett. 2006, 88, 123109-123111. doi:10.1063/1.2187945

18. Ke, L.; Kumar, R. S.; Chua, S. J.; Burden, A. P. Appl. Phys. A: Mater. Sci. Process. 2005, 81, 969-974. doi:10.1007/s00339-004-3134-8

19. Segal, M. Nat. Nanotechnol. 2009, 4, 612-614. doi:10.1038/nnano.2009.279

20. Nasibulin, A. G.; Moisala, A.; Brown, D. P.; Jiang, H.; Kauppinen, E. I. Chem. Phys. Lett. 2005, 402, 227-232. doi:10.1016/j.cplett.2004.12.040

21. Moisala, A.; Nasibulin, A. G.; Brown, D. P.; Jiang, H.; Khriachtchev, L.; Kauppinen, E. I. Chem. Eng. Sci. 2006, 61, 4393-4402. doi:10.1016/j.ces.2006.02.020

22. Nasibulin, A. G.; Pikhitsa, P. V.; Jiang, H.; Kauppinen, E. I. Carbon 2005, 43, 2251-2257. doi:10.1016/j.carbon.2005.03.048

23. Anisimov, A. S.; Nasibulin, A. G.; Jiang, H.; Launois, P.; Cambedouzou, J.; Shandakov, S. D.; Kauppinen, E. I. Carbon 2010, 48, 380-388. doi:10.1016/j.carbon.2009.09.040

24. Susi, T.; Kaskela, A.; Zhu, Z.; Ayala, P.; Arenal, R.; Tian, Y.; Laiho, P.; Mali, J.; Nasibulin, A. G.; Jiang, H.; Lanzani, G.; Stephan, O.; Laasonen, K.; Pichler, T.; Loiseau, A.; Kauppinen, E. I. Chem. Mater. 2011, 23, 2201-2208. doi:10.1021/cm200111b

25. Lanzani, G.; Nasibulin, A. G.; Laasonen, K.; Kauppinen, E. I. J. Phys. Chem. C 2009, 113, 12939-12942. doi:10.1021/jp904200e
26. Lanzani, G.; Susi, T.; Ayala, P.; Jiang, T.; Nasibulin, A. G.; Bligaard, T.; Pichler, T.; Laasonen, K.; Kauppinen, E. I. Phys. Status Solidi B 2010, 247, 2708-2712. doi:10.1002/pssb.201000226

27. Reich, S.; Thomsen, C.; Maultzsch, J. Carbon Nanotubes: Basic Concepts and Physical Properties; John Wiley \& Sons: Berlin, Germany, 2007.

28. Milnera, M.; Kürti, J.; Hulman, M.; Kuzmany, H. Phys. Rev. Lett. 2000, 84, 1324-1327. doi:10.1103/PhysRevLett.84.1324

29. Saito, R.; Dresselhaus, G.; Dresselhaus, M. S. Physical Properties of Carbon Nanotubes; Imperial College Press: London, UK, 1999.

30. Tian, Y.; Jiang, H.; v. Pfaler, J.; Zhu, Z.; Nasibulin, A. G.; Nikitin, T.; Aitchison, B.; Khriachtchev, L.; Brown, D. P.; Kauppinen, E. I. J. Phys. Chem. Lett. 2010, 1, 1143-1148. doi:10.1021/jz100161p

31. Fuhrer, M. S.; Nygård, J.; Shih, L.; Forero, M.; Yoon, Y.-G.; Mazzoni, M. S. C.; Choi, H. J.; Ihm, J.; Louie, S. G.; Zettl, A.; McEuen, P. L. Science 2000, 288, 494-497. doi:10.1126/science.288.5465.494

32. Hamada, N.; Sawada, S.-i.; Oshiyama, A. Phys. Rev. Lett. 1992, 68, 1579-1581. doi:10.1103/PhysRevLett.68.1579

33. Geng, H.-Z.; Kim, K. K.; So, K. P.; Lee, Y. S.; Chang, Y.; Lee, Y. H. J. Am. Chem. Soc. 2007, 129, 7758-7759. doi:10.1021/ja0722224

34. Lee, R. S.; Kim, H. J.; Fischer, J. E.; Thess, A.; Smalley, R. E. Nature 1997, 388, 255-257. doi:10.1038/40822

\section{License and Terms}

This is an Open Access article under the terms of the Creative Commons Attribution License (http://creativecommons.org/licenses/by/2.0), which permits unrestricted use, distribution, and reproduction in any medium, provided the original work is properly cited.

The license is subject to the Beilstein Journal of

Nanotechnology terms and conditions:

(http://www.beilstein-journals.org/bjnano)

The definitive version of this article is the electronic one which can be found at: $\underline{\text { doi:10.3762/bjnano.3.79 }}$ 